\title{
Literacy and Breast Cancer Diagnosis and Treatment among Patients in a Tertiary Health Institution of Lagos Nigeria
}

\author{
Popoola.A.O. ${ }^{1 *}$, Wright.K.O. ${ }^{2}$,Igwilo.A.I. ${ }^{1}$, Sowunmi.A. ${ }^{3}$, Kuyinu.Y.A ${ }^{2}$ \\ ${ }^{I}$ Oncology Unit, Dept of Radiology, Lagos State University Teaching Hospital, Ikeja,Lagos,Nigeria; \\ ${ }^{2}$ Dept of Community Health and Primary Health Care, Lagos State University College of Medicine, \\ Ikeja,Lagos,Nigeria \\ ${ }^{3}$ Dept of Radiotherapy, Lagos University Teaching Hospital, Idiaraba, Lagos, Nigeria;
}

\begin{abstract}
Patients' interpretation of symptoms as a sign of cancer could also influence health seeking behaviour.

This study was undertaken to evaluate the effect of literacy on breast cancer diagnosis and treatment with the hope that the study may enable a more holistic approach to the management, prevention and control of breast cancer.
\end{abstract}

This is a descriptive cross sectional study conducted among breast cancer patients of Lagos State University Teaching Hospital.

A total of 190 histologically diagnosed breast cancer patients were recruited based on a breast cancer prevalence of $13.9 \%$ in a study conducted at Maiduguri, Nigeria (12), using the statistical formula $Z^{2} P Q / d^{2}$.

Out of one hundred and ninety patients studied, mean age calculated was 32years. The peak age range was 5160yrs (22.1\%). There was a statistically significant association between level of education and awareness and practice of the breast cancer screening methods.

Clear communication tailored to patient culture and literacy is essential in improving the awareness and positive attitudes towards the benefits of early breast cancer screening so as to have better outcome.

Keywords: Literacy, Breast Cancer Screening, Mammography, Breast self-examination, Knowledge, Practice

\section{Introduction}

Health literacy is the ability to obtain, process, and understand basic health information and services to make appropriate health decisions which is essential to promoting health (1). On the other hand, low health literacy could adversely impact conditions like cancer incidence, mortality, and quality of life. Several factors may influence health literacy such as reading level, numeracy level, language barriers, cultural appropriateness, format/style, sentence structure, use of illustrations and interactiveness of an intervention. Therefore, people impacted by low health literacy may struggle to understand disease, prevention, and treatment (1).

Patients' interpretation of symptoms as a sign of cancer could also influence health seeking behaviour. In the context of breast cancer, an evaluation of breast symptoms is based on pre-existing knowledge, experience, selfeducation and observation of individuals. Knowledge regarding the variation of symptoms in breast cancer enables patients to interpret the symptoms correctly including the decision to seek medical attention (2).

If untreated, a malignant breast tumor could advances in stage, diminishing a woman's chances of survival. Therefore, identifying factors which contribute to delays in accessing medical intervention has been a continued focus of cancer researchers throughout the world (3).

In high income countries, mortality rates have steadily declined over time as a result of early detection resulting in more favourable breast cancer stage distribution and improved treatment. Conversely the situation in low income countries characterized by medically underserved communities is still bleak. The reasons adduced for the differences in mortality rates include advanced stages at presentation, worse biologic behavior, poor treatment facilities and poor patient acceptance of recommended treatments which have been linked to ignorance, superstition, self-denial, fear of mastectomy and unavailability of treatment facilities(4).

Despite improvements in cancer screening, early detection, and treatment, breast carcinoma remains the most frequently diagnosed cancer in women and the second most common cause of cancer deaths in women in the United States(5). This study was undertaken to evaluate the effect of literacy on breast cancer diagnosis and treatment with the hope that the study may enable a more holistic approach to the management, prevention and control of breast cancer. 


\subsection{Background}

\section{Methodology}

The study was carried out at the Oncology clinic of the Lagos State University Teaching Hospital, Ikeja, Lagos, Nigeria. The hospital is one of the two teaching hospitals in the State comprising of several departments such as Surgery, Medicine, Paediatrics, Obstetrics \& Gynaecology, Radiology, etc.

\subsection{Study Design}

This is a descriptive cross sectional study conducted among breast cancer patients of Lagos State University Teaching Hospital.

\subsection{Sampling Method}

A total of 190 histologically diagnosed breast cancer patients were recruited based on a breast cancer prevalence of $13.9 \%$ in a study conducted at Maiduguri, Nigeria (12), using the statistical formula $Z^{2} \mathrm{PQ} / \mathrm{d}^{2}$. Based on an average of 25 simple randomly picked new cases per month, consenting participants were recruited consecutively until the sample size was completed. Data collection was conducted with the aid of an interviewer administered semi structured questionnaire containing close-ended and a few open-ended questions (which included the bio data and assessment of their knowledge \& practice of breast cancer screening.

Ethical approval was obtained from the Ethics Committee of Lagos State University Teaching Hospital .

Data entry and analysis were done using Epi info version 3.5 (June 9th 2008) and version 7.0 respectively. Findings were represented using tables and charts. The Chi square test was used to test for association between variables with level of significance set at $\mathrm{P}<0.05$.

\subsection{Inclusion Criteria}

-Patients of $18 \mathrm{yrs}$ and above

-Histological confirmation of breast cancer

\subsection{Exclusion Criteria}

-Age below $18 \mathrm{yrs}$

-Patients with psychiatric illness

\section{Result}

Out of a sample size of 190, 38.6\% of respondents had attained tertiary form of education, $27.3 \%$ Secondary, 29\% Primary and 5.1\% has had no form of formal education. (See Fig 1).

Almost all (96.5\%) of respondents who attained a form of tertiary education were aware of breast cancer. (See TABLE 2)

From TABLE 2 , most $(93.3 \%)$ of the respondents who had tertiary education were significantly more aware of breast self-exam, whilst the majority $(66.7 \%)$ of respondents with no formal education had no knowledge of the subject matter. $(\mathrm{P}<0.05)$

There was a statistically significant association between level of education and awareness of mammography as a breast cancer screening method; about $64.1 \%$ of respondents with some form of tertiary education responded positively whereas, $83.3 \%$ of respondents with no formal education were not aware of this method. $(\mathrm{P}<0.05)$ TABLE 2.

Concerning mammographic screening practice, there was no statistically significant association between level of education and mammographic screening. (TABLE 3)

Awareness about early detection and improved survival was significantly higher with increase in educational level. $(\mathrm{P}<0.05)$ TABLE 4

A significant majority $(84.7 \%)$ of respondents with tertiary education practice breast self-examination whilst over half $(60 \%)$ of those with no formal education do not practice breast self-examination $(\mathrm{P}<0.05)$

Over three quarters of respondents with tertiary education were of the opinion that early detection can be helpful in the prevention and control of breast cancer. This was significantly higher with increasing educational level. $(\mathrm{P}<0.05 ; \mathrm{TABLE} 4)$

Of one hundred and ninety patients studied, mean age calculated was 32years. The peak age range was 51-60yrs (22.1\%), followed closely by the $41-50 \mathrm{yrs}(21.1 \%)$, and the $31-40$ years age range (20.5\%) respectively. The $21-$ $30 y e a r s$ age range constituted the group with the least incidence. Most of the participants in the study were females. With a standard deviation of 21.2 and the coefficient of variance calculated was $66.25 \%$. 
TABLE 1 Socio-demographic distribution

\begin{tabular}{|l|l|l|}
\hline Variable & Frequency & $\%$ \\
\hline AGE & & \\
20 & 29 & 15.3 \\
$31-40$ & 13 & 6.8 \\
$41-50$ & 39 & 20.5 \\
$51-60$ & 40 & 21.1 \\
$>60$ & 42 & 22.1 \\
Total & 27 & 14.2 \\
GENDER & 190 & 100.0 \\
Male & & \\
Female & 11 & 5.8 \\
Total & 179 & 94.2 \\
& 190 & 100.0 \\
\hline
\end{tabular}

The mean age was $32 ;$ Standard Deviation $=21.2$

There was a female preponderance $(94.2 \%)$ with the majority being married $(63.3 \%)$

TABLE 2 Awareness on Preventive practices versus Level of Education

\begin{tabular}{|c|c|c|c|c|c|}
\hline $\begin{array}{l}\text { Awareness } \\
\text { Breast Cancer }\end{array}$ & No formal & Primary & Secondary & Tertiary & TOTAL \\
\hline No & $3(33.3 \%)$ & $9(17.6 \%)$ & $11(22.9 \%)$ & $3(4.4 \%)$ & $26(14.8 \%)$ \\
\hline Yes & $6(66.7 \%)$ & $42(82.4 \%)$ & $37(77.1 \%)$ & $65(95.6 \%)$ & $150(85.2 \%)$ \\
\hline Total & $9(100 \%)$ & $51(100 \%)$ & $48(100 \%)$ & $68(100 \%)$ & $\begin{array}{l}176(100 \%) \\
\text { Missing } \\
\text { Data: } 14\end{array}$ \\
\hline \multicolumn{6}{|l|}{$\begin{array}{ll}\text { Breast } & \text { self- } \\
\text { examination } & \\
\end{array}$} \\
\hline No & $4(66.7 \%)$ & $25(54.3 \%)$ & $12(28.3 \%)$ & $4(6.7 \%)$ & $45(29.2 \%)$ \\
\hline Yes & $2(33.3 \%)$ & $21(45.7 \%)$ & $30(71.4 \%)$ & $56(93.3 \%)$ & $109(70.8 \%)$ \\
\hline Total & $6(100 \%)$ & $46(100 \%)$ & $42(100 \%)$ & $60(100 \%)$ & $\begin{array}{l}\text { 154(100\%) } \\
\text { Missing } \\
\text { Data:36 }\end{array}$ \\
\hline \multicolumn{6}{|l|}{$\begin{array}{l}\text { Mammographic } \\
\text { screening }\end{array}$} \\
\hline No & $5(83.3 \%)$ & $39(79.6 \%)$ & $23(54.8 \%)$ & $23(35.9 \%)$ & $90(55.9 \%)$ \\
\hline Yes & $1(16.7 \%)$ & $10(20.4 \%)$ & $19(45.2 \%)$ & $41(64.1 \%)$ & $71(44.1 \%)$ \\
\hline Total & $6(100 \%)$ & $49(100 \%)$ & $42(100 \%)$ & $64(100 \%)$ & $\begin{array}{l}161(100 \%) \\
\text { Missing } \\
\text { Data:29 }\end{array}$ \\
\hline $\begin{array}{l}\text { Chances of } \\
\text { survival with } \\
\text { early detection }\end{array}$ & No formal & Primary & Secondary & Tertiary & Total \\
\hline Fair & $0(0 \%)$ & $4(8 \%)$ & $3(6.3 \%)$ & $1(1.5 \%)$ & $8(4.6 \%)$ \\
\hline Good & $5(55.6 \%)$ & $16(32 \%)$ & $11(22.9 \%)$ & $10(14.9 \%)$ & $42(24.1 \%)$ \\
\hline I don't know & $0(0 \%)$ & $5(10 \%)$ & $3(6.3 \%)$ & $0(0 \%)$ & $8(4.6 \%)$ \\
\hline Very good & $4(44.4 \%)$ & $25(50 \%)$ & $31(64.6 \%)$ & $56(83.6 \%)$ & $116(66.7 \%)$ \\
\hline Total & $9(100 \%)$ & $50(100 \%)$ & $48(100 \%)$ & $67(100 \%)$ & $\begin{array}{l}174(100 \%) \\
\text { Missing } \\
\text { Data: } 16\end{array}$ \\
\hline
\end{tabular}


TABLE 3 Preventive Practices Versus Level of Education

\begin{tabular}{|l|l|l|l|l|l|}
\hline Practices & No formal & Primary & Secondary & Tertiary & Total \\
\hline No & & & & & \\
\hline Yes & $3(60 \%)$ & $21(51.2 \%)$ & $18(45 \%)$ & $9(15.3 \%)$ & $51(35.2 \%)$ \\
\hline Total & $2(40 \%)$ & $20(48.8 \%)$ & $22(55 \%)$ & $50(84.7 \%)$ & $94(64.8 \%)$ \\
& $5(100 \%)$ & $41(100 \%)$ & $40(100 \%)$ & $59(100 \%)$ & $\begin{array}{l}145(100 \%) \\
\text { Missing } \\
\text { Data:45 }\end{array}$ \\
\hline $\begin{array}{l}\text { Mammographic } \\
\text { screening }\end{array}$ & & & & & \\
\hline I don't know & $0(0 \%)$ & $7(16.3 \%)$ & $4(9.5 \%)$ & $0(0 \%)$ & $11(7.4 \%)$ \\
\hline No & $4(57.1 \%)$ & $21(48.8 \%)$ & $24(57.1 \%)$ & $34(59.6 \%)$ & $83(55.7 \%)$ \\
\hline Yes & $3(42.9 \%)$ & $15(34.9 \%)$ & $14(33.3 \%)$ & $23(40.4 \%)$ & $55(36.9 \%)$ \\
\hline Total & $7(100 \%)$ & $43(100 \%)$ & $42(100 \%)$ & $57(100 \%)$ & $149(100 \%)$ \\
& & & & & $\begin{array}{l}\text { Missing } \\
\text { Data:41 }\end{array}$ \\
\hline
\end{tabular}

TABLE 4 Distribution of subjective usefulness of early detection versus level of education LEVEL OF EDUCATION

\begin{tabular}{|l|l|l|l|l|l|}
\hline $\begin{array}{l}\text { Rating of early } \\
\text { detection }\end{array}$ & No formal & Primary & Secondary & Tertiary & Total \\
\hline Helpful & $5(55.6 \%)$ & $10(20.4 \%)$ & $11(23.4 \%)$ & $7(10.8 \%)$ & $33(19.4 \%)$ \\
\hline I don't know & $0(0 \%)$ & $3(6.1 \%)$ & $4(8.5 \%)$ & $1(1.5 \%)$ & $8(4.7 \%)$ \\
\hline Very Helpful & $4(44.4 \%)$ & $36(73.5 \%)$ & $32(68.1 \%)$ & $57(87.7 \%)$ & $129(75.9 \%)$ \\
\hline Total & $9(100 \%)$ & $49(100 \%)$ & $47(100 \%)$ & $65(100 \%)$ & $\begin{array}{l}170(100 \%) \\
\text { Missing } \\
\text { Data:20 }\end{array}$ \\
\hline
\end{tabular}

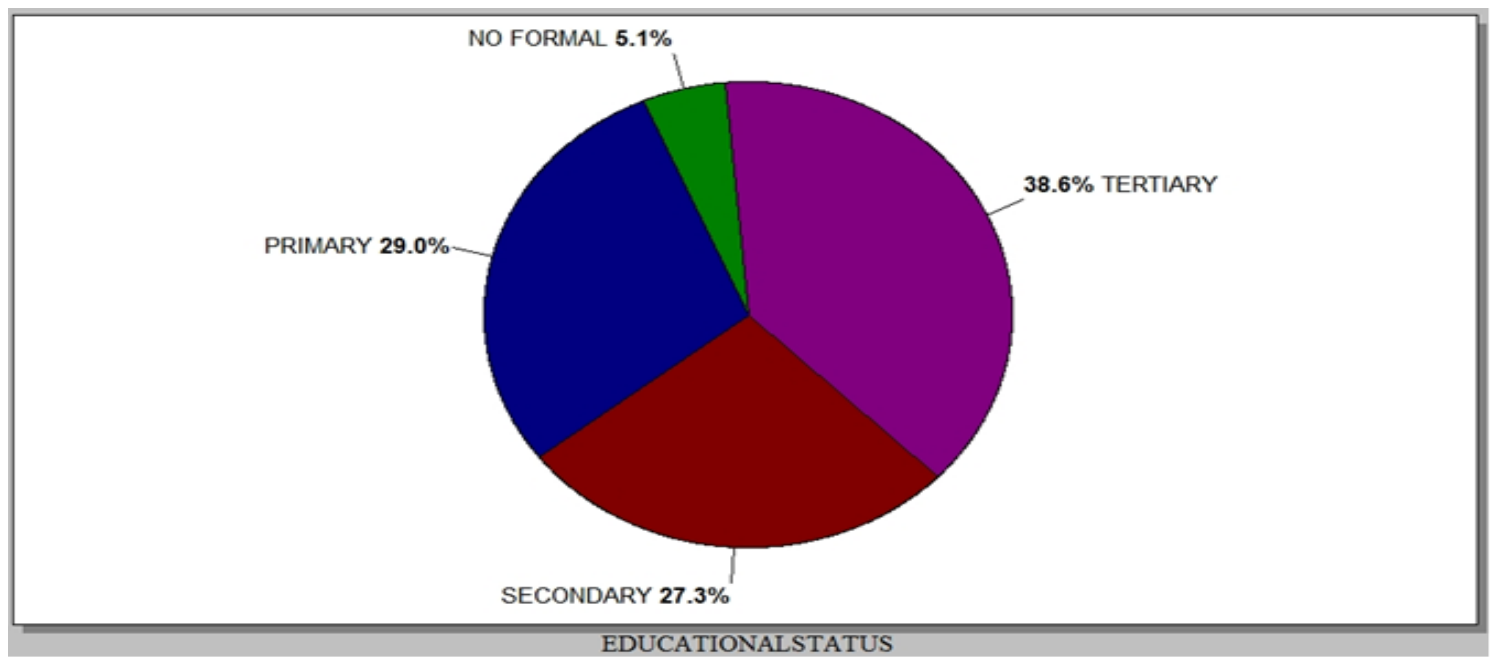

Figure 1 shows the distribution of educational status of respondents

\section{Discussion}

Delay in diagnosis and treatment of breast cancer leads to progression to a late stage and is associated with high mortality and a detrimental effect to survival. (6) About two thirds of respondents in this study were aware that the chance of survival is very good with early diagnosis. (TABLE 4) Furthermore, early diagnosis has been proven to reduce mortality and improve prognosis (7 ). Early detection requires early diagnosis in symptomatic women and regular screening in an asymptomatic woman (8). Moreover, Oluwole et al found improved patient survival in a study on breast cancer staging as a result of improvement in stage at presentation attributable to the provision of culturally relevant educational programs combined with easy access to detection, diagnosis, and treatment of breast cancer(5). 
Health beliefs, health education exposure have been shown to be associated with health-seeking behaviour and formal education has been found to provide an advantage in the understanding of various health issues.(9-12). A Nigerian study on Socio-factors and reasons associated with delay in breast cancer presentation revealed low level of awareness and knowledge about breast cancer resulting in associated with delayed presentation. (13) In addition, breast cancer patients who had low level of education were at higher risk of late presentation. (13) Over half $60 \%$ and $42.9 \%$ of respondents in the present study do not practice breast self-examination and mammographic screening respectively. This is similar to findings by Simian et al who identified disproportionately low rates of cancer screening, diagnostic work up and treatment among people with low health literacy. (14) Despite being in settings where medical care is readily accessible, these individuals experience difficulty comprehending the nuances of cancer screening, diagnosis and treatment. (14).

The majority $(87.7 \%)$ of participants with tertiary education were of the view that early detection of breast cancer could be very helpful. in comparison to $44.4 \%$ of those with no formal education. The relationship between literacy and perception of early detection of breast cancer was statistically significant $(\mathrm{P}=0.02)$.

It is therefore possible that literacy level may influence treatment seeking behavior. It was observed that most $(95.6 \%)$ of respondents who attained a form of tertiary education were aware of breast cancer.(TABLE 2). Similarly, it was observed that level of education appeared to influence the awareness of mammographic screening as a breast cancer screening method; about $64.1 \%$ of those with tertiary education were aware of mammography. (TABLE 4). This is compares favorably with the findings of Akinola et al on Mammography and Mammographic screening in Lagos Nigeria that shows significantly more women with tertiary education and more women working in skilled positions had heard about mammographic screening than women who were less educated or whose work were classified as unskilled_which is similar to findings in this study where Level of education influence the level of awareness of mammography screening and mammography screening and this has been found to influence early diagnosis and resulted in mortality reduction (8)

Mammographic screening has been found to be a sensitive test in detecting breast cancer; In some Swedish studies, single view mammography has detected over $90 \%$ breast cancer while the specificity could be as high as $95 \%$ depending on the quality of mammograms and expertise of the reporting personnel. (15).

Of the available cancer control measures for breast cancer, only mammography screening is recognized to be effective in reducing mortality from breast cancer (16). In a randomized controlled trial in Sweden, in the first 7 years, breast cancer mortality was reduced by $31 \%$ among the study group compared with control group within 7 years.

In this study, $83.6 \%$ of respondents with tertiary education believe early detection of breast cancer will result in very good survival rate while $64.6 \%, 50 \%$ and $44.4 \%$ of secondary, primary and persons with no formal educational level respectively believe early detection will increase patient chance of survival $(\mathrm{P}<0.05)$. (TABLE 4)

Out of one hundred and ninety patients studied, mean age calculated was 32 years. The peak age range was 51-60yrs (22.1\%) with about $64 \%$ between the ages of 30 and60. In most of Western Europe, $40 \%$ of breast cancers are diagnosed at the age of 65 years or more whereas in most Eastern European countries, a relatively lower incidence is reported in the elderly (18). In Nigeria, the peak-age of breast cancer in women is about a decade earlier than in Caucasian women (17).

\section{Conclusion}

A vast array of information and choices face breast cancer patients and patients at risk of developing breast cancer. Clear communication tailored to patient culture and literacy is essential. In addition, attention should be paid to barriers preventing accessibility to mammography, such as costs, shame and accessibility, in order to increase the acceptance index of the target population with respect to breast cancer screening practices; Thus, improving the awareness and positive attitudes towards the benefits of early breast cancer screening so as to have better outcome.

\section{References}

[1]. Carrie K., Shakira.B.;Cultural and Socioeconomic Factors Affecting Cancer Screening, Early Detection and Care in the Latino Population; 2010;Ed;ARNP.

[2]. Bachok.N., Krishna G.R., Mohd.A.R, Nyi .N., Biswa M.B; Diagnosis delay of breast cancer and its associated factors in Malaysian women BMC Cancer; 2011;11: 141

[3]. Noreen.C.F.; Delay versus help seeking for breast cancer symptoms: A critical review of the literature on patient and provider delay sot. sci. med; 1993; vol. 36, no. 12, pp. 1521-1534

[4]. Stanley.N.C.A.,Ochonma.A.E,Eric.C.I.;Acceptance and adherence to treatment among breast cancer patients in Eastern Nigeria; The Breast;Elsevier;2011;s51-s53

[5]. Oluwole S.F, Ali A.O, Adu. A, Blane B.P, Barlow.B, Oropeza.R, Freeman H.P; Impact of a Cancer Screening Program on Breast Cancer Stage at Diagnosis in a Medically Underserved Urban Community. J. Am. Coll. Surg. ;2003;196: 180-188.

[6]. Thongsukai.P.,Chongsuvivatwong.V.,Sriplung.H.;Ovid: Delay in Breast Cancer Care: A study in Thai women;Lippincott Williams \& Wilkins,Inc;2000;Vol 38(1);pg1-8 
[7]. Anderson B.O, Yip C.H, Smith R.A,et al; Guideline implementation for breast healthcare in low-income and middle income countries;overview of the Breast Health Global lnitiative Global Summit 2007. Cancer;2008; 113(8suppl):2221-2234

[8]. Akinola.R.,Wright.K.,Osunfidiya.O.,Orogbemi.O.,Akinola.O.;Mammography and Mammographic screening;Are female patients at a teaching hospital in Lagos,Nigeria aware of these procedures?;Diagn. Interv Radiol;Turkish society of Radiology;2011;17;125-129

[9]. Worden.J.W.,Weisman.A.D;Psychosocial components of lagtime in cancer diagnosis;J. Psycosomat Res; 1975;19;69-79

[10]. Kang.S.H.,Bloom.S.R.,Romano.P.S.;Cancer screening among African-American women:Their use of tests and social support;Am J. Public Health;1994;84;101-103

[11]. Thornton H, Pillarisetti R.R.; 'Breast awareness' and 'breast self examination' are not the same. What do these terms mean? Why are they confused? Eur J Cancer, 2008;44

[12]. Oluwatosin.O.A;Oladepo O;Knowledge of breast cancer and its early detection measures among rural women in Akinyele Local Government Area, Ibadan, Nigeria.BMC;2006;6:271

[13]. Ibrahim N A ,Oludara .M.A;Socio-factors and reasons associated with delay in breast cancer presentation: A study in Nigeria;2012;doi:10.1016/j. breast2012.02.006

[14]. Melissa A. Simon, XinQi Dong, Narissa Nonzee and Charles L. Bennett ; Heeding Our Words: Complexities of Research Among Low-Literacy Populations JCO.2008.20.8231 JCO; 2009;vol. 27 no. 12

[15]. Patric Forrest ;Breast Cancer Screening - Report to Health Ministers of England ,Wales, Scotland and Northern Ireland.

[16]. Anderson BO, Jakesz .R.; Breast cancer issues in developing countries: an overview of the Breast Health Global Initiative. World J Surg; 2008;32, 2578-85

[17]. Okobia, M.N., C.H. Bunker, F.E. Okonofua and U. Osime; Knowledge, attitude and practice of Nigerian women towards breast cancer: A cross-sectional study. World J. Surg. Oncol.,2006; 4: 11, DOI:10.1186/1477-7819-4-11.

[18]. Popoola A.O, Ogunleye O.O, Ibrahim N.A, Omodele F.O, Igwilo A.I :Five Year Survival of Patients with Breast Cancer at the Lagos State University Teaching Hospital, Nigeria Journal of Medicine and Medical Science Research;2012; Volume 1, Issue 2, pp. 24-31. 